\title{
The Road to Creative Achievement: A Latent Variable Model of Ability and Personality Predictors
}

\author{
EMANUEL JAUK*, MATHIAS BENEDEK and ALJOSCHA C. NEUBAUER \\ Department of Psychology, University of Graz, Austria
}

\begin{abstract}
This study investigated the significance of different well-established psychometric indicators of creativity for real-life creative outcomes. Specifically, we tested the effects of creative potential, intelligence, and openness to experiences on everyday creative activities and actual creative achievement. Using a heterogeneous sample of 297 adults, we performed latent multiple regression analyses by means of structural equation modelling. We found openness to experiences and two independent indicators of creative potential, ideational originality and ideational fluency, to predict everyday creative activities. Creative activities, in turn, predicted actual creative achievement. Intelligence was found to predict creative achievement, but not creative activities. Moreover, intelligence moderated the effect of creative activities on creative achievement, suggesting that intelligence may play an important role in transforming creative activities into publically acknowledged creative achievements. This study supports the view of creativity as a multifaceted construct and provides an integrative model illustrating the potential interplay between its different facets. (C) 2013 The Authors. European Journal of Personality published by John Wiley \& Sons Ltd on behalf of European Association of Personality Psychology.
\end{abstract}

Key words: creative achievement; creative activities; creative potential; intelligence; structural equation modelling (SEM)

Creativity is a key concept of human innovation, and much research has been performed to gain a deeper understanding of the creative person. Several perspectives have been used to study creativity, including cognitive, differential, or social psychology approaches (Sternberg \& Lubart, 1999), and each paradigm shed light on different aspects of human creativity. A considerable number of different traits that are related to creativity have been identified. Specifically, creative people are thought to be better able to think in different directions (Guilford, 1950), to share certain patterns of personality traits (Feist, 1998, 2010), to be intrinsically motivated (Amabile, 1983), or to have substantial amounts of domainspecific expertise (Simonton, 1999; Weisberg, 2006). Moreover, the relationship between intelligence and creativity has occupied creativity research from the very beginning (Kaufman $\&$ Plucker, 2011). Thus, a number of different traits are thought to determine the potential for real-life creative accomplishments, but so far, only few attempts have been made to examine their conjoint influence on actual creative achievement. Therefore, this study aims at investigating the relationship between common psychometric indicators of creativity and real-life creative achievement by means of structural equation modelling.

\section{The many faces of creativity}

Trait creativity in terms of psychometrically tested ability can generally be distinguished from real-life creative achievement (Eysenck, 1993, 1995). The former concept is hereby often

*Correspondence to: Emanuel Jauk, Department of Psychology, University of Graz, Maiffredygasse 12b, 8010 Graz, Austria.

E-mail: emanuel.jauk@uni-graz.at labelled creative potential, highlighting that it reflects rather a predictor of real-life creativity than creativity per se (Runco \& Acar, 2012). In line with this distinction, creativity research used to sort into two poles, focusing either on the study of psychometrically tested creative potential or on eminent real-life creativity (also called 'little-C' vs 'big-C'; cf. Kaufman $\&$ Beghetto, 2009). Besides these two approaches, a complementary line of research has emerged that is concerned with real-life creativity within the general population, referred to as everyday creativity (Richards, 1993, 2010). As outlined later, everyday creativity can be considered a behavioural prerequisite of actual creative achievement.

\section{Creative potential}

Creative potential refers to an individual's cognitive ability to generate something novel and useful (Barron, 1955; Runco \& Jaeger, 2012; Stein, 1953) and reflects a normally distributed trait (Eysenck, 1995). It is commonly assessed by means of divergent thinking (DT) tests (Runco, 2010) such as the Torrance Tests of Creative Thinking (Torrance, 1966), the Guilford tests (Wilson et al., 1953), or the Wallach and Kogan tests (Wallach \& Kogan, 1965). DT tests typically involve ill-structured problems for which a variety of possible solutions can be found. In the alternate uses (AU) task, a popular example of a DT task, participants are instructed to find many different creative uses for everyday objects in a given time (for example, brick - 'use for karate demonstration'). The performance in DT tests can be scored with respect to different criteria usually involving ideational fluency, that is, the quantity of ideas, and/or originality, that is, the quality of ideas. Whereas ideational fluency reflects the number of ideas in a given time, ideational originality is commonly 
assessed by means of creativity evaluations of the generated ideas. Recent works using subjective top scoring or snapshot scoring (Benedek et al., in press; Silvia, Martin, \& Nusbaum, 2009; Silvia et al., 2008) found that fluency and originality show discriminant validity and relate differently to other cognitive functions: Ideational fluency draws upon executive functioning, whereas originality is related more strongly to intelligence (Benedek et al., 2012).

\section{Everyday creativity}

The concept of everyday creativity emerged from the study of real-life creative activities within the general (noneminent) population. Everyday creativity is 'defined in terms of human originality at work and leisure across the diverse activities of everyday life' (Richards, 2010, p. 190). Popular measures of everyday creativity are the revised Creative Behavior Inventory (CBI; Dollinger, 2003; based on the original CBI by Hocevar, 1979) and the Biographical Inventory of Creative Behavior (BICB; Batey, 2007) (for a review, see Silvia et al., 2012). Both inventories contain lists of various creative activities (e.g. 'drew picture/cartoon' or 'designed costume/textile') and assess the number of activities performed within a given period. Everyday creativity, assessed by means of biographical measures, was found to be normally distributed just like creative potential (Richards et al., 1988). Thus, an important implication of this concept is that everyone can be involved in creative activities to a varying extent, or a varying degree of absorption. Everyday creativity is considered a behavioural prerequisite of actual creative achievement, or as Richards (2010) put it: 'Everyday creativity can be seen as the ground from which (a later and) more publicly celebrated accomplishment can grow' (p. 193).

\section{Creative achievement}

Creative achievement refers to actual real-life creative accomplishments (such as composing a piece of music, making a scientific discovery, or writing a book; cf. Carson et al., 2005) and is commonly assessed by means of biographical measures. Creative achievement is supposed to follow a highly skewed distribution (Eysenck, 1995), or even a Lotka curve (Simonton, 1999), with the vast majority of the population displaying low levels of creative achievement and only few who attain eminent, high-level creative achievement. A popular measure of creative achievement is the Creative Achievement Questionnaire (CAQ; Carson et al., 2005). The CAQ asks for the attained level of achievement in 10 different domains [for instance, in the domain of music, the levels of achievement range from I have no training or recognized talent in this area (0 points) to My compositions have been critiqued in a national publication (7 points)]. Thus, the CAQ measures primarily qualitative, not quantitative, aspects of creative achievement. The CAQ was found to successfully differentiate between artistic and nonartistic students (Vellante et al., 2011). Discriminant validity evidence comes from the finding that the CAQ is not related to general academic achievement (Hirsh \& Peterson, 2008).

\section{Correlates of real-life creativity}

Dealing first with everyday creativity, the CBI was found to correlate with openness to experiences and tests of creative potential (Dollinger, 2007) as well as self-rated creativity (Wigert et al., 2012). The BICB was found to be related to openness and extraversion (Batey et al., 2010; Furnham \& Bachtiar, 2008; Furnham et al., 2008) and facets of schizotypy (Batey \& Furnham, 2008). No significant influence of intelligence on the BICB was found across several studies (Batey et al., 2010; Furnham \& Bachtiar, 2008; Furnham et al., 2008). As the authors conclude, 'everyday creative accomplishment is not reliant upon intellect' (Batey et al., 2010, p. 535).

The picture looks differently for creative achievement: In an early study, King, Walker, and Broyles (1996) instructed participants to freely list their creative accomplishments and subjected these lists to peer ratings, thus considering not only quantitative but also qualitative aspects of real-life creativity. They found that the quality ratings were best predicted by an interaction between creative potential and openness to experiences; that is, high creative potential and high openness. Moreover, quality ratings were significantly related to intelligence $(r=.27)$. Further studies involving the CAQ found significant correlations with openness to experiences (Silvia, Kaufmann \& Pretz, 2009; Silvia et al., 2012) and with intelligence (Carson et al., 2003; Kéri, 2011). A recent meta-analysis estimated the relationship of creative achievement with creative potential as $r=.22$ and that of creative achievement with intelligence as $r=.17$ (Kim, 2008).

It hence can be concluded that openness is a consistent correlate of both everyday creative activities and creative achievement, whereas intelligence is exclusively related to actual creative achievement. Moreover, it is interesting to note that creative achievement displays a highly skewed distribution (Silvia et al., 2012), whereas creative activities and most other relevant traits do not. As noted by several researchers (e.g. Eysenck, 1995; Simonton, 1999), skewed distributions are likely to arise from a multiplicative, synergistic, rather than additive interplay of various factors. This suggests that several traits have to appear in combination in order to allow for high creative achievement. Although the involvement in everyday creative activities can be considered a necessary condition for creative achievement (i.e. it is hardly possible to make a significant contribution to a field without being regularly engaged in it), relevant cognitive and noncognitive factors may determine the actual and attainable level of achievement.

\section{The role of intelligence in creative achievement}

We propose that intelligence plays a central role in creative achievement for two reasons. First, there is a robust relationship between intelligence and ideational originality, thus pointing to common cognitive mechanisms underlying divergent and convergent thinking processes (Benedek et al., 2012; Cropley, 2006; Nusbaum \& Silvia, 2011a). Second, creative achievements generally represent extensive, complex tasks that may draw upon intelligence: Putting creative ideas into practice usually requires a good deal of planning and elaboration in the long run, and although intelligence-related demands may differ between creative domains (Getzels \& Csikszentmihalyi, 1972), being of higher intelligence will generally not be detrimental 
to creative endeavours. It is well known from other fields of research that intelligence is a central predictor of general career success (cf. Schmidt \& Hunter, 2004).

In line with these considerations, intelligence was found to predict creative achievement in longitudinal studies: Plucker's (1999) reanalysis of longitudinal data originally collected by Torrance (1972) found latent factors of both intelligence and creative potential to be predictive of real-life achievements as much as 20 years later. Creative potential was the strongest predictor of creative achievement, but intelligence explained incremental variance over and above creative potential. Further studies dealing with Torrance's data reported that creative potential and intelligence were significant predictors of creative achievement in a 40 -year follow-up (Cramond et al., 2005). In a 50-year follow-up, Runco et al. (2010) found that creative potential was associated with personal achievements (which can be considered everyday creative activities), whereas publicly acknowledged creative achievement was related to an interaction between intelligence and creative potential. Wai et al. (2005) found Scholastic Aptitude Test scores within a gifted group of 13-year-olds to predict creative achievement 20 years later. Although measures of creative potential were not used, this study vividly demonstrates that intelligence is an important factor even within high-ability groups. In a 45-year longitudinal study, Feist and Barron (2003) found that intelligence at age 27 predicts lifetime creative achievement at age 72 . Additionally, personality traits such as self-confidence and openness explained incremental variance over and above intelligence.

Another prominent concept regarding the interplay between intelligence and creativity is the threshold hypothesis. It assumes that intelligence fosters creativity only up to a threshold of about 120 IQ points and thereafter loses its impact. The threshold hypothesis is commonly investigated using measures of creative potential (cf. Kaufman \& Plucker, 2011). Although a meta-analysis of the previous literature yielded no evidence for a threshold effect (Kim, 2005), recent studies using new methodology found partial support for the threshold hypothesis (Jauk et al., 2013; Karwowski \& Gralewski, 2013). Specifically, our recent results suggest that the intelligence threshold depends on the employed criterion: Although we observed threshold effects for indicators of creative potential, we found no evidence for an intelligence threshold in creative achievement. Thus, intelligence may foster creative achievement throughout the whole ability range.

\section{The present research}

This study aims to investigate the influence of common psychometric indicators of creativity (including openness, ideational fluency, ideational originality, and intelligence) on everyday creative activities and actual creative achievement. Because the involved constructs are known to share substantial amounts of variance and may display complex interdependencies, we set up latent variable structural equation models to avoid the typical fallacies of correlational research (cf. Silvia, 2008). Because the existing measures of everyday creativity and creative achievement differ substantially with respect to the included domains of creativity, we used a newly devised inventory that captures both constructs in a standardized way across the same major domains of real-life creativity.

On the basis of the findings presented earlier, we hypothesized that both creative activities and creative achievement are predicted by openness to experiences and creative potential. Moreover, we expect that everyday creative activities predict actual creative achievement. This assumption has strong face validity but has to our knowledge not yet been tested empirically. Finally, we assume that intelligence predicts creative achievement but not creative activities. Because creative achievement is thought to depend upon several factors that have to appear in combination, we also tested whether intelligence actually moderates the influence of creative activities on creative achievement.

\section{METHOD}

\section{Participants}

Participants were recruited via a local free newspaper as well as the university's mailing lists. We included people with an age between 18 and 55 years, German as the mother tongue, and the absence of any mental or neurological disorders. After excluding one person because of excessive missing data, the final sample consisted of $N=297$ participants (101 men) who took part in a larger study on cognitive ability, motivation, and personality (also Jauk et al., 2013). Participants were on average 30 years old $(S D=10.68)$. Of the participants, $16 \%$ had 9 years of schooling, $60 \%$ had 12 years of schooling, and $24 \%$ had a university degree. Participants were paid for taking part in the study.

\section{Measures}

\section{Creative potential}

Creative potential was measured by means of three AU tasks and three instances (IN) tasks. In the AU tasks, participants were required to find as many novel and uncommon uses as possible for a can, a knife, and a hairdryer. In the IN tasks, participants were instructed to figure out many novel and uncommon solutions to the problems 'What can make noise', 'What can be elastic', and 'What could one use for quicker locomotion'? The tasks were administered on a PC, and participants were required to enter their ideas via a keyboard. Each task lasted for 2 minutes. Ideational fluency was defined as the number of ideas given in the task. Ideational originality was assessed by means of subjective top 3 scoring, which reflects the rated creativity of the three best ideas within each task (Benedek et al., in press). To this end, participants were asked to identify their most creative ideas, and the three best ideas were then rated for creativity. Ratings were performed by four raters (three women) experienced in DT assessment on a 4-point scale ranging from 1 (not creative) to 4 (very creative). Mean interrater reliabilities were $\mathrm{ICC}=0.80$ in the AU tasks and ICC $=0.69$ in the IN tasks. Ratings were then averaged across raters. The subjective top-scoring method was shown to overcome the confounding of ideational originality and fluency while concurrently providing highly reliable 
and valid scores (Benedek et al., in press; Silvia et al., 2008). Total scores of ideational fluency and originality were computed by averaging across the six DT tasks.

\section{Creative activities and creative achievement}

In order to assess participant's everyday creative activities and actual creative achievements, we administered a newly devised inventory of creative activities and achievements (ICAA). ${ }^{1}$ This inventory assesses creative activities and achievements in eight domains, including literature, music, arts and crafts, creative cooking, sports, visual arts, performing arts, and science and engineering. Rather than using existing measures such as the BICB and the CAQ, the use of the ICAA appeared necessary to ensure that activity and achievement scores refer to the same domains of creative accomplishment. The ICAA was piloted in a sample of about 350 people and further validated in smaller samples of art students.

The activities scale of the ICAA was constructed in the style of existing scales that measure everyday creativity such as the revised CBI (Dollinger, 2003; Hocevar, 1979) or the BICB (Batey, 2007). Participants report on a 5-point scale how often they carried out certain activities within the last 10 years (never, one to two times, three to five times, 5-10 times, and more than 10 times). Responses are assigned $0-4$ points. The ICAA includes six relevant activities for each of the eight domains, ensuring equal representation of all domains. For example, in the literature domain, participants are presented with statements such as 'wrote a short literary work (e.g., poem, short story)' or 'wrote a blog entry'. Domain scores are obtained by summing points across domain-specific activities, and a total score can be computed by further summing across domains.

The achievement scale of the ICAA is conceptually similar to the CAQ by Carson et al. (2005). Participants are asked to indicate which achievements they have already attained in each of the eight domains. The achievements range from I have never been engaged in this domain (0 points) to I have already sold some of my work in this domain (10 points). As in the CAQ, all applying levels can be checked, but in contrast to the CAQ, no extra points are given for repeatedly attaining certain achievements (e.g. selling one's work twice or three times).

In addition to the ICAA, we administered a German translation of the CAQ to obtain evidence of convergent validity for the ICAA achievements scale. Moreover, we asked participants to freely list their creative achievements (similar to King et al., 1996) in order to check for relevant achievements in domains other than those included in the ICAA and the CAQ.

\section{Intelligence}

General intelligence $(g)$ was assessed by means of four subtests of the Intelligence Structure Battery (IntelligenzStruktur-Batterie, INSBAT; Arendasy et al., 2004), which is theoretically grounded on the Cattell-Horn-Carroll model

\footnotetext{
${ }^{1}$ The ICAA is available in English and German and can be obtained from the
} second author upon request. of intelligence (for an overview, see McGrew, 2009). Four computer-based tests were selected to reflect a broad representation of $g$ including figural inductive reasoning (figural induktives Denken), verbal short-term memory (verbales Kurzzeitgedächtnis), arithmetic flexibility (arithmetische Flexibilität), and word meaning (Wortbedeutung). Detailed descriptions of the single tests are given in Jauk et al. (2013).

The INSBAT is based on item response theory and allows for tailored testing. Target reliability for each scale was set to $\alpha=.60$, which results in an average of 10 items per test, or an average duration of 10 minutes per test.

\section{Openness to experiences}

We assessed openness to experiences by means of the Big Five Structure Inventory (Big-Five Struktur Inventar; Arendasy et al., 2011). The test is based on item response theory and was shown to have good correlations with the German Big Five questionnaire NEO-PI-R, while internal consistency is even higher (Arendasy et al., 2011). Openness was assessed by means of six facets (openness to fantasy, aesthetics, feelings, actions, ideas, and norms/values) with 10 items each, thus resulting in a total number of 60 items for the factor. The test was administered without time restriction.

\section{Procedure}

The experiment took place in a computer laboratory. Groups of up to 10 people performed all tests on standard desktop computers. Two experimenters informed participants about the purpose of the study and were present during the experimental session. Because this study was part of a larger screening for further investigations, participants also completed motivation scales and a speed of information processing task. The order of tasks was as follows: After completing a sociodemographic questionnaire and motivation scales, participants performed the INSBAT for about 50 minutes followed by a break of 15 minutes. Next, participants worked on the speed of information processing task, the tasks of creative potential, the ICAA, the CAQ, and finally the Big Five Structure Inventory. The total test session took about 2.5 hours. The procedure was approved by the Ethics Committee of the University of Graz.

\section{RESULTS}

\section{Descriptive statistics and intercorrelations}

Figure 1 shows the distributions of the ICAA activities and achievements scores. As predicted by theory, the achievements scale displayed positive skewness (skewness $=1.78, p<.01$; kurtosis $=4.66, p<.01$ ), whereas the activities scale was normally distributed (skewness $=0.38, n s$; kurtosis $=-0.23, n s$ ). Measures of creative potential, openness to experiences, and intelligence were all normally distributed. Internal consistency of the ICAA was assessed by means of Cronbach's $\alpha$ across the eight scales of the inventory. Coefficients were $\alpha=.78$ for the activities scale and $\alpha=.71$ for the achievements scale. 

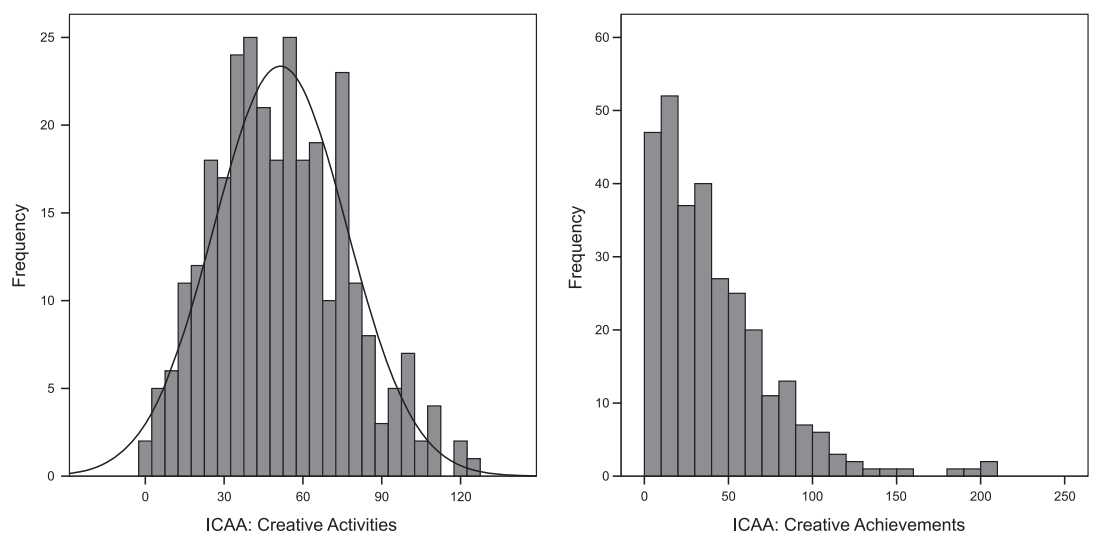

Figure 1. Frequency distributions of the Inventory of Creative Activities and Achievements (ICAA) scales.

Table 1 displays the descriptive statistics and intercorrelations of the observed variables. Measures of real-life creativity (activities and achievements) showed significant positive correlations with all other variables including openness, ideational fluency, and originality, as well as intelligence. The highest correlations for the creative activities scale were found with the creative achievement measures, and with openness. The ICAA achievement scale was highly correlated with the CAQ $\left(r=.68 ; r_{\mathrm{S}}=.70\right)$ supporting its convergent validity. Moreover, a substantial positive correlation was observed between intelligence and originality (Table 1). The latent relationships between these constructs are presented in the following section.

\section{Model specification}

A structural equation model was established in order to analyse the latent relationships between real-life creativity measures (creative activities and creative achievements), creative potential (ideational fluency and originality), openness to experiences, and intelligence. Model estimation was performed with MPLUS 5.2 using the maximum likelihood procedure with robust standard errors (MLR) in order to account for nonnormality in the data. All regression coefficients were standardized. We followed a two-step modelling approach (Anderson \& Gerbing, 1988) in which identified parts of the measurement models were evaluated separately before testing the structural relationships among the latent constructs. This procedure ensures that the latent constructs are adequately measured before examining their structural relationships. Modifications that were made to the measurement models are described in the following section. Parameter estimates of the measurement models are not presented separately because they virtually equalled the results of the final model.

\section{Measurement models}

In each measurement model, the first indicator (left to right or top to bottom in Figure 2) of each latent variable was fixed to 1. The measurement models of creative potential consisted of two separate two-factor hierarchical confirmatory factor analysis (CFA) models for ideational fluency and ideational originality as depicted in Figure 2. Each score was defined by the two DT task types (i.e. fluency was measured by AUf and INf and originality by AUo and INo), which again were defined by the three tasks per task type (e.g. AUf1, AUf2, and AUf3). Because fluency and originality reflect two different indicators that were assessed using the same six tasks, error correlations were free to vary between each pair of indicators in order to account for task-specific variance (e.g. the error term of AUf1 was allowed to correlate with the error of AUo1). For the measurement of openness to experiences, the six facets were regressed onto a single latent factor. Four error correlations were specified between the six facets (Figure 2) in order to reach adequate fit of the measurement model. It is well known that CFA models of the Big Five have to deal with cross-loadings and error correlations in order to

Table 1. Descriptive statistics and intercorrelations of the employed measures

\begin{tabular}{|c|c|c|c|c|c|c|c|c|c|}
\hline & Min & Max & $M(S D)$ & 2 & 3 & 4 & 5 & 6 & 7 \\
\hline ICAA: activities (1) & 0.00 & 124 & $51.42(25.36)$ & 0.66 & 0.52 & 0.13 & 0.49 & 0.32 & 0.28 \\
\hline ICAA: achievements (2) & 0.00 & 208 & $40.72(35.15)$ & & 0.68 & 0.27 & 0.37 & 0.28 & 0.27 \\
\hline CAQ total (3) & 0.00 & 151 & $12.97(16.03)$ & & & 0.17 & 0.29 & 0.39 & 0.13 \\
\hline Intelligence (4) & -4.33 & 2.40 & $-0.56(1.10)$ & & & & 0.14 & 0.20 & 0.40 \\
\hline Openness (5) & -2.07 & 2.03 & $0.16(0.78)$ & & & & & 0.26 & 0.19 \\
\hline CP: fluency (6) & 4.17 & 27.17 & $12.37(3.89)$ & & & & & & 0.18 \\
\hline CP: originality (7) & 1.35 & 2.47 & $2.02(0.18)$ & & & & & & \\
\hline
\end{tabular}

Note: $N=297$. Intelligence and openness scores reflect person parameters according to the item response theory model. Intelligence scores are based on the average of the subtests figural inductive reasoning, verbal short-term memory, and arithmetic flexibility (for details, see Method section).

ICAA, Inventory of Creative Activities and Achievements; CAQ, Creative Achievement Questionnaire; CP, creative potential.

Correlation coefficients above $r=.11$ are significant at $p=.05$, coefficients exceeding $r=.15$ are significant at $p=.01$. 


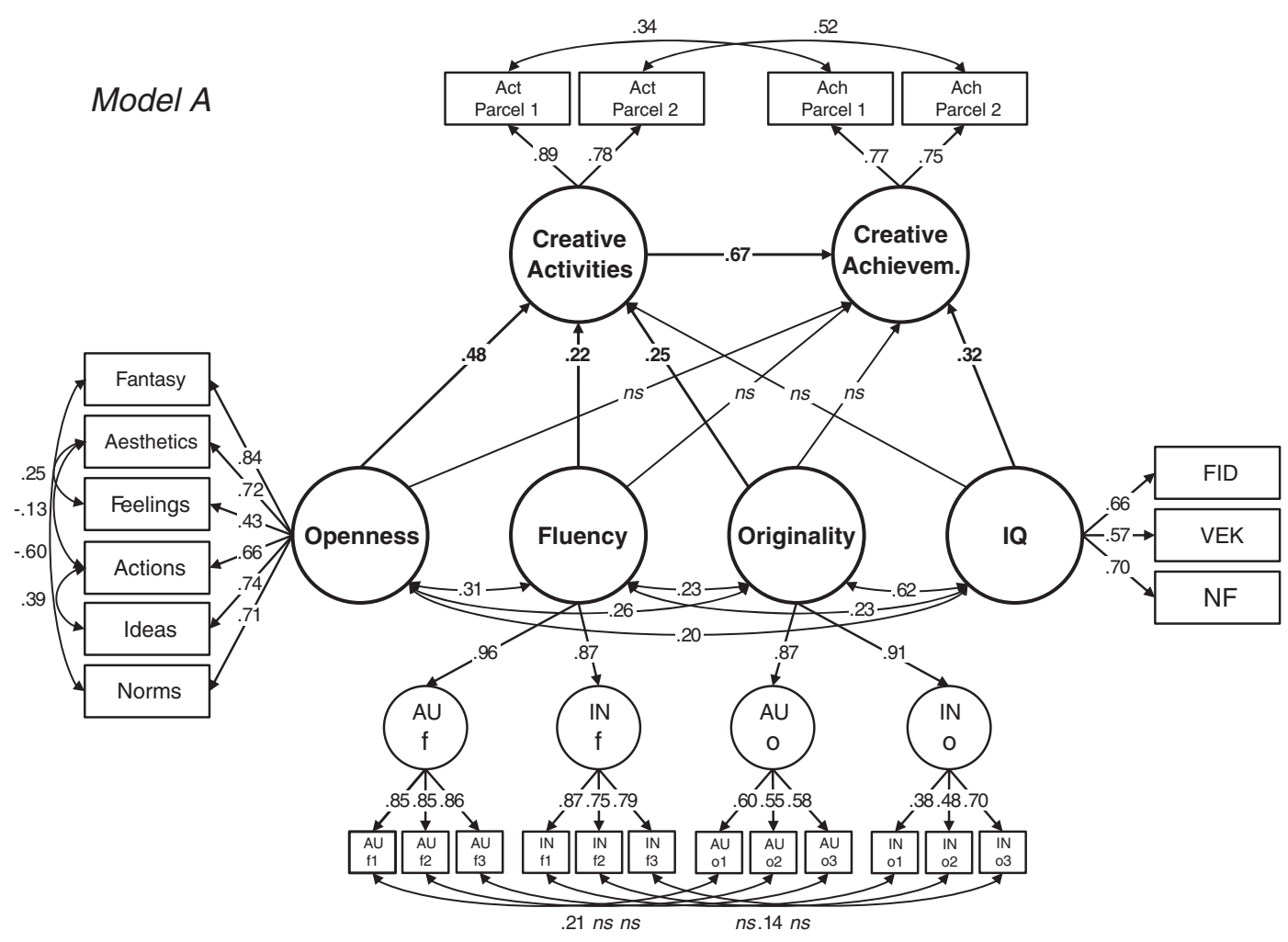

Figure 2. Structural equation model for the prediction of creative activities and achievements. Error terms are not displayed. Detailed explanations and abbreviations are given in the Results section.

reach acceptable fit to the data (cf. Marsh et al., 2010). For the measurement of general intelligence, the four subtests were regressed onto one latent factor. The subscale word meaning was excluded from further calculations because variance explained in the observed variable was not significant $\left(R^{2}=6 \%, p=.06\right)$.

Creative activities and achievement, as assessed by the ICAA, were each defined by two item parcels that comprised the first four and second four domain scales of the inventory (i.e. literature, music, handicraft, and creative cooking vs sports, visual arts, performing arts, and science and engineering, respectively). Similar to the measurement model of creative potential, error correlations between the corresponding parcels were allowed in order to account for unique (domain-specific) variance. Despite the fact that each domain has its unique portion of variance, this procedure allowed us to investigate domain-general variance inherent to creative activities and achievements. Although some concerns have been expressed towards the use of parcels, it can well be justified when the goal of a study is to understand latent structure of a set of constructs rather than the structure of a set of items (Little et al., 2002).

\section{Structural model}

The effects of the predictor variables openness to experiences, ideational fluency, ideational originality, and intelligence were tested on creative activities and achievements in the structural part of the model. Thus, all paths were free to vary and, although we did not expect intelligence to influence creative activities, we did not rule out this possibility a priori.
Moreover, creative activities were assumed to influence creative achievement. Correlations between openness, ideational fluency, originality, and intelligence were all free to vary as these constructs are known to be correlated.

\section{Latent variable model results}

We assessed model fit using the $\chi^{2}$ test, the comparative fit index (CFI), the root mean square error of approximation (RMSEA), and the standardized root mean square residual (SRMR) (Beauducel \& Wittmann, 2005; Hu \& Bentler, 1998, 1999).

The model estimation converged to an admissible solution. Although we obtained a significant $\chi^{2}$ test, all other indices indicate good fit $\left(\chi^{2}(244)=348.82, p<.01 ; \mathrm{CFI}=0.965\right.$; RMSEA $=0.038 ; 90 \%$ CI $[0.029,0.047], p_{\text {RMSEA }}<0.05=.99$; SRMR =0.052). Because sensitivity of the $\chi^{2}$ test is known to increase with sample size, a common practice is to evaluate model fit by $\chi^{2} / d f$. This model showed a $\chi^{2} / d f$ of 1.43 , which is below the commonly employed criterion of 2 indicating good model fit (Byrne, 1989, p. 55).

The prediction of creative activities and creative achievement All correlations between the four predictor variables openness, ideational fluency and originality, and intelligence were statistically significant. Openness to experiences showed moderate correlations with all other variables. Moreover, latent factors of ideational originality and fluency were moderately correlated. There was a strong association between ideational originality and intelligence, whereas the correlation between fluency and intelligence was markedly lower (Figure 2). 
The results of the structural regression model indicate that openness to experiences is the strongest predictor of creative activities $(\beta=.48, p<.001)$. In addition, ideational fluency $(\beta=.22, p<.01)$ and ideational originality $(\beta=.25, p<.05)$ were significant predictors of creative activities, but intelligence was not $(\beta=-.13, p=.23)$. The overall variance explained in the latent variable creative activities was $R^{2}=44 \%$. Turning to the prediction of creative achievement, we find that the contrary holds true: Here, neither openness nor the indicators of creative potential had significant effects. Instead, creative achievement is predicted by creative activities $(\beta=.67, p<.001)$ and intelligence $(\beta=.32, p<.001)$. Openness, ideational fluency, and ideational originality had no significant effects (openness: $\beta=.05, p=.45$; fluency: $\beta=.04, p=.62$; originality: $\beta=-.12, p=.23)$. The predictors accounted for $R^{2}=60 \%$ of the variance in the latent variable.

\section{Indirect effects on creative achievement}

We also investigated whether openness and creative potential have an indirect influence on creative achievement, that is, if creative activities mediate their effects on creative achievement. We found that openness had a significant indirect effect on creative achievement $(\beta=.32, p<.001)$. Moreover, the indirect effects of ideational fluency $(\beta=.15, p<.01)$ and originality $(\beta=.17, p<.05)$ were significant, too. Thus, the effects of all three variables on creative achievement are fully mediated by creative activities.

\section{Intelligence as a moderator variable}

In order to test our hypothesis that it takes intelligence to convert creative activities into creative achievements, we examined if intelligence moderates the influence of creative activities on creative achievement. Thus, from the model presented earlier (model $A$ ), we set up a moderation model $A^{\prime}$ that involved a latent interaction term between intelligence and creative activities. ${ }^{2}$ The resulting model converged to an admissible solution and showed a good fit $\left(\chi^{2}(393)=468.64\right.$, $p<.01 ; \chi^{2} / d f=1.19 ; \mathrm{CFI}=0.979 ; \mathrm{RMSEA}=0.025 ; 90 \% \mathrm{CI}$ $[0.015,0.034], p_{\text {RMSEA }<0.05}=1.00 ;$ SRMR $\left.=0.051\right)$. Factor

\footnotetext{
${ }^{2}$ Moderation analyses with continuous latent variables follow the same principle as originally described for manifest variables by Baron and Kenny (1986): If $M$ moderates the influence of $X$ on $Y$, the product term $M * X$ should explain variance in $Y$ over and above the main effects of $X$ and $M$ (also Little et al., 2007). Latent product terms are set up by multiplying each combination of the single indicators of $X$ and $M$. Collinearity between $M * X, X$, and $M$ must be avoided by means of orthogonalization. We set up a moderation model for the latent variables creative activities $(X)$ and intelligence $(M)$ and tested their conjoint influence on creative achievement $(Y)$. Orthogonalization was performed by means of the residual-centring approach as described by Little et al. (2006). This involves the following: (i) building the product terms between each pair of indicators of $X$ and $M$; (ii) regressing each of these product terms onto all indicators in a standard multiple regression model; and then (iii) using the residuals of each regression analysis (i.e. the proportion of variance in the interaction term that cannot be explained by a linear combination of its constituent terms) as latent variable indicators. Given two indicators of creative activities and three indicators of intelligence, we used six regression residuals as indicators of the latent interaction variable. Error correlations were allowed between each pair of indicators that shared one of their constituent variables. Correlations between the latent interaction variable and its constituent latent variables as well as the other predictors were set to zero (Little et al., 2006).
}

loadings of the indicators of the latent interaction variable ranged from 0.42 to 0.81 .

We found a significant interaction between intelligence and creative activities on creative achievement $(\beta=.28$, $p<.001)$ while all other parameter estimates remained virtually unaffected (Figure 3). Thus, the influence of creative activities on creative achievement is moderated by intelligence. The total variance explained in creative achievement was $R^{2}=67 \%$.

A comparison of the moderation model $A^{\prime}$ with the initial model $A$ by means of the Akaike information criterion (AIC) shows that the initial model should be preferred over the moderation model $\left(\mathrm{AIC}_{A}\right.$ : 32351.14, $\mathrm{AIC}_{A^{\prime}}$ : 46933.88). Nonetheless, the AIC is a parsimony-adjusted index that punishes a higher number of free parameters (which are needed to establish the latent interaction), and yet little is known concerning the comparison of models with and without latent interaction variables established by means of the residual-centring approach. The indirect effects of openness and creative potential were also significant in the moderation model $A^{\prime}$ (openness: $\beta=.31, p<.001$; Ideational fluency: $\beta=.14, p<.01$; Ideational originality: $\beta=.16, p<.05$ ). Thus, the indirect effects are moderated by intelligence in terms of moderated mediation.

\section{DISCUSSION}

The aim of this study was to disentangle several aspects of the multifaceted construct of creativity: We tested to which extent real-life creativity, in terms of everyday creative activities and actual creative achievement, is determined by creative potential, openness to experiences, and intelligence. The results indicate that these cognitive and noncognitive traits play different roles for the realization of creative activities and creative achievement.

Everyday creative activities include minor creative accomplishments (e.g. drawing a picture or writing a piece of music) representing personal achievements, whereas creative achievement usually refers to publically acknowledged achievements (Kaufman \& Beghetto, 2009; Runco et al., 2010). Although the extent of engagement in creative activities depends upon openness to experiences and creative potential (i.e. the ability

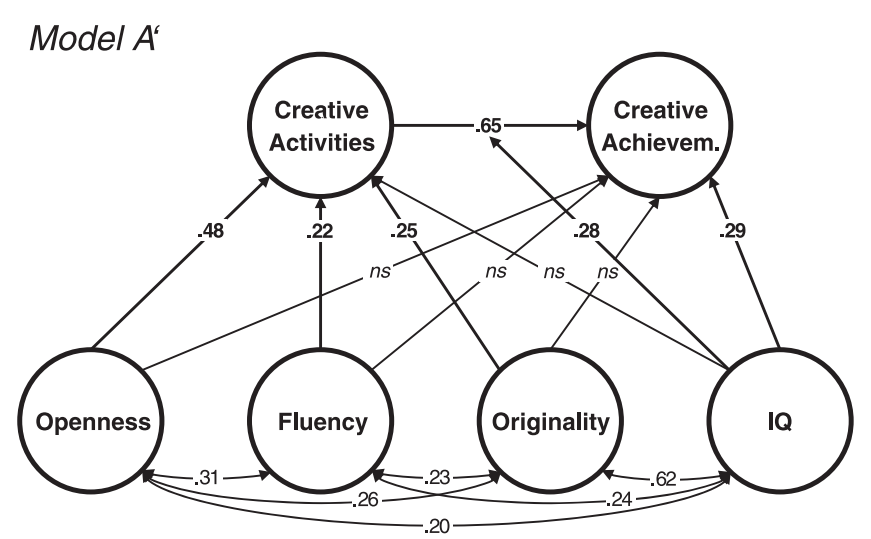

Figure 3. Structural part of the latent moderation model. 
to produce original ideas and to produce many of them), actual creative achievement, in turn, depends conjointly on intelligence and the amount of creative activities.

These findings are well in accordance with the literature suggesting that everyday creative activities are to be distinguished from actual creative achievement (Kaufman $\&$ Beghetto, 2009). Our results further suggest that everyday creativity and creative achievement should not be viewed as competing but rather as complementary concepts. Everyday creative activities can help to bridge a gap from creative potential, in terms of tested ability, to actual creative achievement: We found that openness and creative potential exert their influence on creative achievement via the path of creative activities. People high in openness and high in creative potential engage more frequently in creative activities (and perform minor/personal creative accomplishments), but intelligence may determine whether these remain at the level of personal accomplishments or may become publically acknowledged achievements.

\section{Openness and creative potential foster creative activities}

Openness to experiences was the strongest predictor of creative activities. This finding is well in line with the literature suggesting that openness is a consistent and significant correlate of various aspects of creativity (Batey \& Furnham, 2006; Feist, 1998, 2010; Nusbaum \& Silvia, 2011a), especially everyday creativity (Silvia, Nusbaum, Berg, Martin, \& O'Conner, 2009). Open people are curious, have a need for variety, and actively seek out new activities (McCrea and Costa, 1997), which may lead them to engage in different everyday creative activities. Moreover, openness is thought to reflect an 'investment trait' relevant to creativity (ChamorroPremuzic \& Furnham, 2005) and fosters the acquisition of a broader general knowledge (Cho et al., 2010). Taken together, open people may engage in creative activities more frequently and thereby acquire a basis of experience and knowledge upon which possible later achievements can build.

Creative potential indicators, ideational fluency and originality, both had incremental effects on the amount of creative activities over and above openness to experiences. Everyday creative activities such as interpreting a piece of music, making up a recipe, or designing a website hence could be considered open-ended problem situations that depend on the ability to come up with a variety of original ideas. Our findings further support the view that ideational fluency and ideational originality are discriminable aspects of creative potential. Both indicators predicted unique variance in creative activities. Moreover, although fluency was related more strongly to openness to experiences, we observed a strong correlation between originality and intelligence. This is in line with recent research demonstrating that the qualitative measure of ideational originality draws strongly upon intelligence, whereas ideational fluency, as a purely quantitative indicator, rather depends upon executive functioning (Benedek et al., 2012; Gilhooly et al., 2007; Nusbaum \& Silvia, 2011b). Concerning intelligence, our recent analyses pointed to a nonlinear relationship between intelligence and ideational originality: Originality may strongly draw upon intelligence in low-intelligence to average-intelligence individuals, whereas other factors might determine the originality of brighter people's ideas (Jauk et al., 2013). In summary, openness can be viewed as a personality requisite of creative activities, whereas ideational fluency and originality can be considered cognitive requirements that are relevant to the performance of creative activities.

\section{The role of intelligence in creative achievement}

The finding that intelligence is important for creative achievement supports the view that successful creators are not solely creative but also bright (Kéri, 2011; Sternberg \& Lubart, 1996; Sternberg \& O'Hara, 1999). This notion is well in line with previous research suggesting that intelligence is crucial for all kinds of complex problem solving and may especially be needed to put creative ideas into action (Sternberg \& O'Hara, 1999). Although intelligence and creative activities contribute additively to creative achievement, results from the moderation model suggest that the interplay of both factors can explain additional variance in creative achievement. Moreover, because creative activities mediate the influence of openness and creative potential on creative achievement, this model actually reflects a moderated mediation. These findings are in accordance with the notion that skewed distributions, repeatedly observed for measures of creative achievement, arise by means of interactional effects (Eysenck, 1995; Simonton, 1999). That is, only people that are both highly intelligent and performing many creative activities (supported by their openness and creative potential) may reach high creative achievement. Finally, these results corroborate the observation that intelligence generally does not predict the exertion of creative activities (although latent factors of intelligence and ideational originality displayed a large amount of shared variance) but is particularly relevant to creative achievement (e.g. Batey et al., 2010).

\section{A multifactorial model of creative achievement}

Creative achievement is generally believed to be determined by several cognitive and noncognitive factors (Eysenck, 1995). Specifically, certain combinations of relevant traits are thought to form the basis for actual creative achievement (Simonton, 1999). Although openness and creative potential had no direct effects on creative achievement in our latent variable model, they did have indirect effects, mediated by creative activities. That is, openness and creative potential may not directly increase creative achievement, but they foster the exertion of creative activities. Specifically, openness may lower the behavioural threshold for engaging in creative activities (Feist \& Barron, 2003). That is, when given the chance to engage in a creative activity, an open person is more likely to actually seize this opportunity. Creative potential, in terms of the ability to come up with many novel ideas, may then facilitate the exertion of creative activities and lead to encouraging experiences, which, in turn, may result in sustained engagement in a certain field. By this means, a person may acquire a broad base of experience and knowledge in a certain domain. Finally, it may depend on intelligence to 
which extent one can convert the acquired skills or expertise into notable creative achievements (Sternberg \& Lubart, 1996).

\section{Limitations and directions for future research}

A key assumption to the latent variable models presented in this study is that creative achievement is causally preceded by creative activities. In our view, this assumption has strong face validity (e.g. it is hardly possible to win a prize for a musical composition without being engaged in the field of music). Nonetheless, the structural equation models presented here are not capable of testing this assumption. Only a longitudinal study could clarify this issue empirically. Moreover, it has to be noted that the influence of creative activities on creative achievement is likely to be overestimated because of shared method variance (assessment within the same inventory). Future studies could use different indicators of creative activities and creative achievement to address this issue.

Several scholars have stressed the importance of expertise on creative achievement (e.g. Simonton, 1994, 2004; Weisberg, 2006). Because we did not directly assess the amount of time or engagement that a person devoted to a certain field, we had only limited possibilities to explore these relationships. We did, however, take up participant's age as a predictor variable in the structural equation models. Age did not have significant effects on creative activities or creative achievement. Contrary to what could be expected, age displayed negative zero-order correlations with creative achievements $(r=-.23)$ and creative activities $(r=-.12)$. Thus, these effects are most likely to reflect cohort differences (older generations may have had less favourable conditions for creative endeavours).

Closely related to the acquisition of expertise is the importance of motivational variables in creative achievement (e.g. Amabile, 1983). Creative achievement usually requires a good deal of hard work, and motivation can be considered an important prerequisite in order to stick to a certain task over a longer period. Especially intrinsic motivation is assumed to be closely related to real-life creativity (Hennessey, 2003, 2010). The assessment of intrinsic motivation, however, makes sense only with regard to a certain domain or activity (e.g. a person may be intrinsically motivated in the field of music, but not in science). Although this study employed a domain-general approach, future studies exploring domainspecific models of real life could examine potential additional effects of intrinsic motivation. In this context, it was also noted that intelligence-related demands may vary between different fields of creative endeavour (Getzels \& Csikszentmihalyi, 1972). For instance, achievement in the field of music was found to be more strongly related to intelligence than creative potential as compared with other domains (Kim, 2008).

\section{CONCLUSIONS}

This study investigated the relationships between different aspects of the multifaceted construct of creativity and specifically aimed at linking real-life creativity with common indicators of trait creativity. We examined a model that traces creativity from its cognitive components over everyday creative activities to actual creative achievement. We found that the exertion of everyday creative activities depends upon openness to experiences and creative potential. Turning creative activities into actual achievements, in contrast, depends on intelligence. Thus, this study integrated several lines of research, resulting in a more comprehensive picture of the interplay between relevant determinants of creative achievement.

\section{ACKNOWLEDGEMENTS}

This research was supported by a grant from the Austrian Science Fund (FWF): P23914. The authors wish to express their gratitude to Michaela Lenzhofer and Martin Wammerl as well as Maike Sitter for their help in organizing and conducting the test sessions.

\section{REFERENCES}

Amabile, T. M. (1983). The social psychology of creativity. New York: Springer.

Anderson, J. C., \& Gerbing, D. W. (1988). Structural equation modeling in practice: A review and recommended two-step approach. Psychological Bulletin, 103, 411-423.

Arendasy, M., Hornke, L. F., Sommer, M., Häusler, J., WagnerMenghin, M., Gittler, G., ... Wenzl, M. (2004). Manual Intelligence-Structure-Battery. INSBAT. Mödling: Schuhfried Gmbh.

Arendasy, M., Sommer, M., \& Feldhammer, M. (2011). Manual Big-Five Structure Inventory BFSI. Mödling: Schuhfried Gmbh.

Baron, R. M., \& Kenny, D. A. (1986). The moderator-mediator variable distinction in social psychological research: Conceptual, strategic, and statistical considerations. Journal of Personality and Social Psychology, 51, 1173-1182.

Barron, F. (1955). The disposition towards originality. Journal of Abnormal and Social Psychology, 51, 478-485.

Batey, M. (2007). A psychometric investigation of everyday creativity (Unpublished doctoral dissertation). University College, London.

Batey, M., \& Furnham, A. (2006). Creativity, intelligence, and personality: A critical review of the scattered literature. Genetic, Social, and General Psychology Monographs, 132, 355-429.

Batey, M., \& Furnham, A. (2008). The relationship between measures of creativity and schizotypy. Personality and Individual Differences, 45, 816-821.

Batey, M., Furnham, A., \& Saffiulina, X. (2010). Intelligence, general knowledge and personality as predictors of creativity. Learning and Individual Differences, 20, 532-535.

Beauducel, A., \& Wittmann, W. W. (2005). Simulation study on fit indexes in CFA based on data with slightly distorted simple structure. Structural Equation Modeling, 12, 41-75.

Benedek, M., Franz, F., Heene, M., \& Neubauer, A. C. (2012). Differential effects of cognitive inhibition and intelligence on creativity. Personality and Individual Differences, 53, 480-485.

Benedek M., Mühlmann, C., Jauk, E., \& Neuabauer, A. C. (in press). Assessment of divergent thinking by means of the subjective topscoring method: Effects of the number of top-ideas and timeon-task on reliability and validity. Psychology of Aesthetics, Creativity, and the Arts.

Byrne, B. M. (1989). A primer of LISREL. New York: Springer Verlag.

Carson, S. H., Peterson, J. B., \& Higgins, D. M. (2003). Decreased latent inhibition is associated with increased creative achievement in high-functioning individuals. Journal of Personality and Social Psychology, 85, 499-506. 
Carson, S. H., Peterson, J. B., \& Higgins, D. M. (2005). Reliability, validity, and factor structure of the creative achievement questionnaire. Creativity Research Journal, 17, 37-50.

Chamorro-Premuzic, T., \& Furnham, A. (2005). Personality and intellectual competence. Mahwah: Lawrence Erlbaum Associates.

Cho, S. H., Nijenhuis, J. T., van Vianen, A. E., Kim, H.-B., \& Lee, K. H. (2010). The relationship between diverse components of intelligence and creativity. The Journal of Creative Behavior, 44, 125-137.

Cramond, B., Matthews-Morgan, J., Bandalos, D., \& Zuo, L. (2005). A report on the 40-year follow-up of the Torrance Tests of Creative Thinking: Alive and well in the new millennium. Gifted Child Quarterly, 49, 283-291.

Cropley, A. (2006). In praise of convergent thinking. Creativity Research Journal, 18, 391-404.

Dollinger, S. J. (2003). Need for uniqueness, need for cognition, and creativity. Journal of Creative Behavior, 37, 99-116.

Dollinger, S. J. (2007). Creativity and conservatism. Personality and Individual Differences, 43, 1025-1035.

Eysenck, H. J. (1993). Creativity and personality: Suggestions for a theory. Psychological Inquiry, 4, 147-178.

Eysenck, H. J. (1995). Genius: The natural history of creativity. New York: Cambridge University Press.

Feist, G. J. (1998). A meta-analysis of personality in scientific and artistic creativity. Personality and Social Psychology Review, 2, 290-309.

Feist, G. J. (2010). The function of personality in creativity: The nature and nurture of the creative personality. In J. C. Kaufman, \& R. J. Sternberg (Eds.), The Cambridge handbook of creativity (pp. 113-130). New York: Cambridge University Press.

Feist, G. J., \& Barron, F. X. (2003). Predicting creativity from early to late adulthood: Intellect, potential, and personality. Journal of Research in Personality, 37, 62-88.

Furnham, A., \& Bachtiar, V. (2008). Personality and intelligence as predictors of creativity. Personality and Individual Differences, 45, 613-617.

Furnham, A., Batey, M., Anand, K., \& Manfield, J. (2008). Personality, hypomania, intelligence and creativity. Personality and Individual Differences, 44, 1060-1069.

Getzels, J. W., \& Csikszentmihalyi, M. (1972). The creative artist as an explorer. In J. McVicker Hunt (Ed.), Human intelligence (pp. 182-192). Oxford: Transaction Books.

Gilhooly, K. J., Fioratou, E., Anthony, S. H., \& Wynn, V. (2007). Divergent thinking: Strategies and executive involvement in generating novel uses for familiar objects. British Journal of Psychology, 98, 611-625.

Guilford, J. P. (1950). Creativity. American Psychologist, 5, 444-454.

Hennessey, B. A. (2003). The social psychology of creativity. Scandinavian Journal of Educational Research, 47, 253-271.

Hennessey, B. A. (2010). The creativity-motivation connection. In J. C. Kaufman \& R. J. Sternberg (Eds.), The Cambridge handbook of creativity (pp. 342-365). New York: Cambridge University Press.

Hirsh, J. B., \& Peterson, J. B. (2008). Predicting creativity and academic success with a "fake-proof" measure of the big five. Journal of Research in Personality, 42, 1323-1333.

Hocevar, D. (1979). The development of the Creative Behavior Inventory (CBI). Paper presented at the annual meeting of the Rocky Mountain Psychological Association (ERIC Document Reproduction Service No. Ed. 170 350).

Hu, L. T., \& Bentler, P. M. (1998). Fit indices in covariance structure modeling: Sensitivity to underparameterized model misspecification. Psychological Methods, 3, 424-453.

Hu, L. T., \& Bentler, P. M. (1999). Cutoff criteria for fit indexes in covariance structure analysis: Conventional criteria versus new alternatives. Structural Equation Modeling, 6, 1-55.

Jauk, E., Benedek, M., Dunst, B., \& Neubauer, A. C. (2013). The relationship between intelligence and creativity: New support for the threshold hypothesis by means of empirical breakpoint detection. Intelligence, 41, 212-221.

Karwowski, M., \& Gralewski, J. (2013). Threshold hypothesis: Fact or artifact? Thinking Skills and Creativity, 8, 25-33.
Kaufman, J. C., \& Beghetto, R. A. (2009). Beyond big and little: The four C model of creativity. Review of General Psychology, $13,1-12$.

Kaufman, J. C., \& Plucker, J. A. (2011). Intelligence and creativity. In R. J. Sternberg \& S. B. Kaufman (Eds.), The Cambridge handbook of intelligence (pp. 771-783). Cambridge: Cambridge University Press.

Kéri, S. (2011). Solitary minds and social capital: Latent inhibition, general intellectual functions and social network size predict creative achievements. Psychology of Aesthetics, Creativity, and the Arts, 5, 215-221.

Kim, K. H. (2005). Can only intelligent people be creative? A metaanalysis. The Journal of Secondary Gifted Education, 16, 57-66.

Kim, K. H. (2008). Meta-analyses of the relationship of creative achievement to both IQ and divergent thinking test scores. Journal of Creative Behavior, 42, 106-130.

King, L. A., Walker, L. M., \& Broyles, S. J. (1996). Creativity and the five-factor model. Journal of Research in Personality, 30, 189-203.

Little T. D., Bovaird, J. A., \& Widaman, K. F. (2006). On the merits of orthogonalizing powered and product terms: Implications for modeling interactions among latent variables. Structural Equation Modeling, 13, 497-519.

Little, T. D., Card, N. A., Bovaird, J. A., Preacher, K. J., \& Crandall, C. S. (2007). Structural equation modeling of mediation and moderation with contextual factors. In T. D. Little, J. A. Bovaird, \& N. A. Card (Eds.), Modeling contextual effects in longitudinal studies (pp. 207-230). Mahwah: Lawrence Erlbaum Associates Publishers.

Little, T. D., Cunningham, W. A., Shahar, G., \& Widaman, K. F. (2002). To parcel or not to parcel: Exploring the question, weighting the merits. Structural Equation Modeling, 9, 151-173.

Marsh H. W., Lüdtke, O., Muthén, B., Asparouhov, T., Morin, A. J. S., \& Trautwein, U. (2010). A new look at the big five factor structure through exploratory structural equation modeling. Psychological Assessment, 22, 471-491.

McCrea, R. R., \& Costa, P. T. (1997). Conceptions and correlates of openness to experience. In R. Hogan, J. A. Johnson, \& S. R. Briggs (Eds.), Handbook of personality psychology (pp. 825-847). San Diego: Academic Press.

McGrew, K. (2009). CHC theory and the human cognitive abilities project: Standing on the shoulders of the giants of psychometric intelligence research. Intelligence, 37, 1-10.

Nusbaum, E. C., \& Silvia, P. J. (2011a). Are openness and intellect distinct aspects of openness to experience? A test of the $\mathrm{O} / \mathrm{I}$ model. Personality and Individual Differences, 51, 571-574.

Nusbaum, E. C., \& Silvia, P. J. (2011b). Are intelligence and creativity really so different? Fluid intelligence, executive processes, and strategy use in divergent thinking. Intelligence, 39, 36-45.

Plucker, J. A. (1999). Is the proof in the pudding? Reanalyses of Torrance's (1958 to present) longitudinal data. Creativity Research Journal, 12, 103-114.

Richards, R. (1993). Everyday creativity, eminent creativity, and psychopathology. Psychological Inquiry, 4, 212-217.

Richards, R. (2010). Everyday creativity: Process and way of lifeFour key issues. In J. C. Kaufman, \& R. J. Sternberg (Eds.), The Cambridge handbook of creativity (pp. 189-215). Cambridge: Cambridge University Press.

Richards, R., Kinney, D. K., Benet, M., \& Merzel, A. P. C. (1988). Assessing everyday creativity: Characteristics of the lifetime creativity scales and validation with three large samples. Journal of Personality and Social Psychology, 54, 476-485.

Runco, M. A. (2010). Divergent thinking, creativity, and ideation. In J. C. Kaufman, \& R. J. Sternberg (Eds.), The Cambridge handbook of creativity (pp. 413-446). Cambridge: Cambridge University Press.

Runco, M. A., \& Acar, S. (2012). Divergent thinking as an indicator of creative potential. Creativity Research Journal, 24, 66-75.

Runco, M. A., \& Jaeger, G. J. (2012). The standard definition of creativity. Creativity Research Journal, 24, 92-96.

Runco M. A., Millar, G., Acar, S., \& Cramond, B. (2010). Torrance tests of creative thinking as predictors of personal and public 
achievement: A fifty-year follow-up. Creativity Research Journal, $22,361-368$.

Schmidt, F. L., \& Hunter, J. (2004). General mental ability in the world of work: Occupational attainment and job performance. Journal of Personality and Social Psychology, 86, 162-173.

Silvia, P. J. (2008). Another look at creativity and intelligence: Exploring higher-order models and probable confounds. Personality and Individual Differences, 44, 1012-1021.

Silvia, P. J., Kaufman, J. C., \& Pretz, J. E. (2009). Is creativity domain-specific? Latent class models of creative accomplishments and creative self-descriptions. Psychology of Aesthetics, Creativity, and the Arts, 3, 139-148.

Silvia, P. J., Martin, C., \& Nusbaum, E. C. (2009). A snapshot of creativity: Evaluating a quick and simple method for assessing divergent thinking. Thinking Skills and Creativity, 4, 79-85.

Silvia, P. J., Nusbaum, E. C., Berg, C., Martin, C., O'Connor, A. (2009). Openness to experience, plasticity, and creativity: Exploring lower-order, high-order, and interactive effects. Journal of Research in Personality, 43, 1087-1090.

Silvia, P. J., Wigert, B., Reiter-Palmon, R., \& Kaufman, J. C. (2012). Assessing creativity with self-report scales: A review and empirical evaluation. Psychology of Aesthetics, Creativity, and the Arts, 6, 19-34.

Silvia, P. J., Winterstein, B. B., Willse, J. T., Barona, C. M., Cram, J. T., Hess, K. I., ... Richard, C. A. (2008). Assessing creativity with divergent thinking tasks: Exploring the reliability and validity of new subjective scoring methods. Psychology of Aesthetics, Creativity, and the Arts, 2, 68-85.

Simonton, D. K. (1994). Greatness: Who makes history and why. New York: Guilford Press.

Simonton, D. K. (1999). Origins of genius. Darwinian perspectives on creativity. Oxford: Oxford University Press.

Simonton, D. K. (2004). Creativity in science: Chance, logic, genius, and zeitgeist. Cambridge, UK: Cambridge University Press.
Stein, M. I. (1953). Creativity and culture. Journal of Psychology, $36,31-322$.

Sternberg, R. J., \& Lubart, T. I. (1996). Investing in creativity. American Psychologist, 51, 677-688.

Sternberg, R. J., \& Lubart, T. I. (1999). The concept of creativity: Prospects and paradigms. In R. J. Sternberg (Ed.), Handbook of creativity (pp. 3-15). Cambridge: Cambridge University Press.

Sternberg, R. J., \& O'Hara, L. A. (1999). Creativity and intelligence. In R. J. Sternberg (Ed.), Handbook of creativity (pp. 251-272). Cambridge: Cambridge University Press.

Torrance, E. P. (1966). Torrance tests of creative thinking: Directions manual and scoring. Princeton: Personnel Press.

Torrance, E. P. (1972). Career patterns and peak creative achievements of creative high school students 12 years later. Gifted Child Quarterly, 16, 75-88.

Vellante, M., Zucca, G., Preti, A., Sisti, D., Rocchi, M. B. L., Akiskal, K. K., \& Akiskal, H. S. (2011). Creativity and affective temperaments in non-clinical professional artists: an empirical psychometric investigation. Journal of Affective Disorders, 135, 28-36.

Wai, J., Lubinski, D., \& Benbow, C. P. (2005). Creativity and occupational accomplishments among intellectually precocious youths: An age 13 to age 33 longitudinal study. Journal of Educational Psychology, 97, 484-492.

Wallach, M. A., \& Kogan, N. (1965). Modes of thinking in young children: A study of the creativity-intelligence distinction. New York: Holt, Rinehart and Winston.

Weisberg, R. W. (2006). Creativity: Understanding innovation in problem solving, science, invention, and the arts. Hoboken: John Wiley \& Sons.

Wigert, B., Reiter-Palmon, R., Kaufman, J. C., \& Silvia, P. J. (2012). Perfectionism: The good, the bad, and the creative. Journal of Research in Personality, 46, 775-779.

Wilson, R. C., Guilford, J. P., \& Christensen, P. R. (1953). The measurement of individual differences in originality. Psychological Bulletin, 50, 362-370. 